\title{
Molecular Detection and Sequencing for S1 Glycoprotein Gene of Bronchitis Virus of 2016 Epidemic from Sindh and Punjab
}

\author{
Ahmad Umer Sultan 1, Muhammad Danish Mehmood ${ }^{1 *}$, Rameez Hassan ${ }^{2}$, Huma Anwar', \\ Sana Noreen ${ }^{1}$, Faisal Amin ${ }^{3}$, Sajjad Hussain ${ }^{4}$ \\ ${ }^{1}$ Ottoman Pharma (Immuno Division), Lahore, Pakistan \\ ${ }^{2}$ Institute of Molecular Biology and Biotechnology, University of Lahore, Lahore, Pakistan \\ ${ }^{3}$ Grand Parent Diagnostic Laboratory, Lahore, Pakistan \\ ${ }^{4}$ Veterinary Research Institute, Lahore, Pakistan \\ Email: *drdanishmehmood@gmail.com
}

How to cite this paper: Sultanm A.U., Mehmood, M.D., Hassan, R., Anwar, H., Noreen, S., Amin, F. and Hussain, S. (2018) Molecular Detection and Sequencing for S1 Glycoprotein Gene of Bronchitis Virus of 2016 Epidemic from Sindh and Punjab. Advances in Bioscience and Biotechnology, 9, 649-660.

https://doi.org/10.4236/abb.2018.912044

Received: October 30, 2018

Accepted: December 15, 2018

Published: December 18, 2018

Copyright $\odot 2018$ by authors and Scientific Research Publishing Inc. This work is licensed under the Creative Commons Attribution International License (CC BY 4.0).

http://creativecommons.org/licenses/by/4.0/

\begin{abstract}
Infectious Bronchitis (IB) is highly contagious disease of commercial poultry causing substantial economic loses by producing poor quality meat in broilers and effecting production in breeder birds. The causative agent has been reported as most hazardous pathogen among other infectious agent even after being immunized with multi-variant strain vaccine. Currently, different strain such as H-120, 4/91 and D274 have been used extensively for immunoprophylaxis against velogenic strain across Pakistan with minimal protection reported. In current study PCR analysis was used to investigate the molecular nature of IB isolates from Punjab and Sind province of Pakistan in 2016 epidemics. Total of 100 tracheal samples were considered for virus inoculation in 10 days old chicken embryonated eggs. The IBV infected amniotic fluid was neutralized with monoclonal antisera of H-120, 4/91 and D274 strains. The IBV screened samples were subjected for RNA extraction and subsequent to PCR using type specific primer of each strain. The amplified product of $840 \mathrm{bp}$ was sequenced through Sanger sequencing. On the basis of PCR results, four similar amplified products from both regions were obtained showing similarities in agarose gel electrophoresis, but they differ from each other on the basis of nucleotides sequence. Phylogenetic analysis revealed that nucleotide sequences of isolates from Karachi were similar to the IBV H-120, Mass-41 and Connecticut 46 reference strains. Whereas, isolates from the Punjab province are analogous to the Mans-2, Mans-3, 9/41(UK) but did not show significant similarity with other reference strain. Therefore, it is recommended that use of $\mathrm{M}-41$ and $\mathrm{H}-120$ in vaccine production could be effective measure against velogenic infectious agent in Sindh particularly in Karachi, whereas, it would be better to incorporate either of the variant
\end{abstract}


GQ281656.1, AY279533.1 in vaccine because of their highest level of resemblance with genetically sequenced isolates from Lahore and its surroundings.

\section{Keywords}

Infectious Bronchitis Virus, S1 Glycoprotein, Polymerase Chain Reaction, Virus Neutralization Test, Molecular Evolutionary Genetics Analysis

\section{Introduction}

Infectious bronchitis (IB) is a highly contagious respiratory problem characterized by respiratory, digestive, reproductive and renal infections in domestic poultry and wild avian species [1]. It hits the flock at any age but the young flocks are considered more prone to the disease. The disease is clinically manifested by tracheal rales, nasal discharge and sneezing, coughing, loss of body weight, sinusitis, increased water intake, depression, lethargy and poor growth in broilers. Avian infectious bronchitis is of more importance in layer and breeder birds as compared to broilers as it induces great drop in egg production and sometimes may damage oviduct resulting in to permanent loss of egg production. In case of reproductive damage the causative agent resides in the oviduct and affects the internal and external quality of eggs such as rough, misshapen eggs bearing collar on the surface of the egg, emergence of thin watery and mixed internal contents [2] [3] [4] [5]. The first report of IB by Schalk and Hawn referred to a highly contagious disease in young chicks with respiratory symptoms in North Dakota, USA in 1931 [6]. The disease is also termed as infectious bronchitis of young chicks which are caused by infectious bronchitis virus (IBV) [7]. The causative agent is corona virus which is enveloped, and single stranded RNA virus belonging to family coronaviridae.

Thereafter and to date, a wide range of different IBV serotypes and genotypes have been detected around the world causing heavy economic losses [8]. IB is responsible for severe financial losses to the poultry industry despite the wide use of live attenuated and inactivated vaccines. IB still remains one of the most important poultry diseases in Korea and many other countries of the world. A number of IBV serotypes have been identified worldwide, and some of these serotypes cannot be controlled by heterologous serotyped vaccines [9] [10] [11].

IB is one of the major problems having many variants prevailing in the environment making vaccination ineffective in all age groups and species. The pathogen is categorized into two main types, classic and variant strains. Both of the strain categories vary from each other to such an extent that antibodies produced against one strains do not confer cross protection against other upon vaccination [12] [13].

IB virus has a potential to alter its genetic structure according to the surrounding environment. The ability to induce genetic variation will eventually help viruses to evade the immune response and causes outbreaks in vaccinated 
flocks. The generation of genetic variants is thought to result from a few amino acid changes in the spike (S) glycoprotein of IBV [14]. The spike (S) of the virus is a glycoprotein in nature and anchors $S$ protein into the lipid bilayer of the virion and plays a crucial role in disease pathogenesis. The IBV S gene consists of 1162 amino acids, and is cleaved into two sub-units, the $\mathrm{N}$-terminal S1 subunit (535 amino acids) and the C-terminal S2 subunit (627 amino acids). The S1 subunit contains virus neutralization and serotype specific antigenic determinants that are responsible for binding to the host cell, neutralization and immune response [15] [16] [17] [18].

To prevent IB infection in broilers, breeders, and layer birds, IB variants such as Massachusetts-41 (M-41), H-120 and D-274 have been included in the vaccination schedule. However, the problem still persists even after excessive vaccination and stern biosecurity during routine monitoring of the flocks. It was also observed that high anti-body titer in non-vaccinated flocks (8.7\%) are those against M-41strain as well [19], there by suggesting the presence of this and possibly other IBV strains in Pakistan.

The current study was undertaken to investigate the prevalent velogenic strain of IB on the basis of Molecular Evolutionary Genetics Analysis (MEGA), in different areas of province Punjab and Sindh, Pakistan. Moreover, the results of current study shall help the poultry farmers to select the appropriate vaccine strain for effective immunoprophylaxis against IB virus in the respective areas.

\section{Materials and Methods}

\subsection{Chicken Embryonated Eggs}

Ten days old 100 embryonated chicken eggs were purchased from Big Bird Poultry breeding company located at Raiwind road, Lahore. External surface of the eggs were disinfected with pyodine-ethanol (10\%) solution and subsequently shifted to $37^{\circ} \mathrm{C}$ incubator until inoculation of virus.

\subsection{Viruses and Antisera}

Lungs and trachea of broilers affected with infectious bronchitis were isolated from Lahore, Kasur, Sheikhupura and Gujranwala districts of Punjab and Surjani town, Super highway, Dhabeji regions of Karachi, Pakistan during outbreaks in 2016. Infectious Bronchitis virus infected mucous membrane was extracted with the help of sterile throat swabs. The swab was suspended in $3 \mathrm{ml}$ of sterile normal saline $(0.85 \% \mathrm{NaCl}$ solution). The suspension was thoroughly shacked and centrifuged at $3000 \mathrm{rpm}$ for 10 minutes. The supernatant was passed through 0.5 micron size syringe filter and single dose of $0.1 \mathrm{ml}$ was used for inoculation into chicken embryonated eggs through allantoic sac route and incubated at $37^{\circ} \mathrm{C}$ for 72 hours. Harvested IBV infected amnioto-allantoic fluid was preserved at $-80^{\circ} \mathrm{C}$ for further investigation. To perform virus neutralization test $1 \mathrm{ml}$ lyophilized vial of monoclonal antisera of each strain was obtained from Ottoman Pharma (Immuno division). 


\subsection{Virus Neutralization Test (VNT)}

Equal concentration (50 ul) of each isolate was mixed with known antisera and inoculated into 10 day old chicken embryonated eggs which were than incubated at $37^{\circ} \mathrm{C}$ for 72 hours. The eggs were harvested separately and the remaining fluid was subsequently subjected to RT-PCR as described by Hofsad [20].

\subsection{RNA Extraction}

Viral RNA was isolated from 12 isolates including positive control as described by [21]. Briefly, sodium dodecyl sulphate (Merck-USA)(final concentration 20\% [w:v] and proteinase K (Bio world) (final concentration $250 \mu \mathrm{g} / \mathrm{ml}$ ) were added to allantoic fluid, incubated for $5 \mathrm{~min}$ at $56^{\circ} \mathrm{C}$ for 30 minutes followed by addition of $400 \mu \mathrm{l}$ phenol chloroform (100\%) isoamyl alcohol (100\%) (Thermo Fisher-USA). The mixture was centrifuged at $14,000 \mathrm{rpm}$ and the sediment was mixed with $100 \mu \mathrm{l}$ of ethanol (Sigma-Aldrich USA) (80\%). After isolation RNA was re-suspended in $40 \mu \mathrm{l}$ distilled $\mathrm{H}_{2} \mathrm{O}$ and was stored at $-50^{\circ} \mathrm{C}$ until RT-PCR analysis.

\subsection{Molecular Detection of IBV Using One-Step RT-PCR}

Viral RNA was isolated from 12 isolates including positive control as described by [21]. The RT reaction contained $4 \mu \mathrm{l}$ of $10 \times$ PCR buffer, $2 \mu \mathrm{l}$ of $10 \mathrm{mM}$ each dNTP (Merck-USA), $1 \mu \mathrm{l}$ each of forward and reverse oligo, $1.5 \mu \mathrm{l}$ of $80 \mathrm{mM}$ $\mathrm{Mgcl}_{2}$ (Merck-USA) and $9 \mu \mathrm{l}$ of the RNA solution. Total of $20 \mu \mathrm{l}$ reaction volume was obtained by adding $3 \mu \mathrm{l}$ of sterile distilled water. Master mix for all samples were prepared without mixing RNAs of viral strains. Equal volume $(11 \mu \mathrm{l})$ of master mix was added in $0.2 \mathrm{ml}$ PCR tube and relevant RNAs were mixed to the respective tubes and incubated at $42^{\circ} \mathrm{C}$ for 60 minutes followed by incubation at $72^{\circ} \mathrm{C}$ for 10 minutes in thermal cycler (ABS-USA).

The prepared cDNA of the samples were subjected to PCR amplification of the desired S1 glycoprotein gene. For the PCR reaction, 3 ul of 10× PCR buffer, $0.5 \mu \mathrm{l}$ of each forward ('5-CTTTTGGCACTATGTAGTGC-3') and reverse primer ('5-ATTAGTAAAAGGYTAYAAGCCATCTG-3'), $3.5 \mu$ of $80 \mathrm{mM} \mathrm{MgCl}_{2}$ and $1 \mu \mathrm{l}$ of Taq DNA polymerase (Perkin-Elmer Cetus, Norwalk, Conn.) were added to the reaction mixture. Reaction volume was obtained by adding $13 \mu \mathrm{l}$ of sterile nuclease free water. Master mix was prepared without adding cDNA and reverse primers of viral strains. Equal volume $(19.5 \mu \mathrm{l})$ of master mix was added in $0.2 \mathrm{ml}$ PCR tube. $5 \mu \mathrm{l}$ of relevant $\mathrm{cDNAs}$, forward and reverse primers were mixed and added to the relevant tubes. The tubes were incubated in thermal cycler (Applied Biosystems) with an initial denaturation at $95^{\circ} \mathrm{C}$ for 2 minutes followed by incubation, 30 cycles of denaturation at $95^{\circ} \mathrm{C}$ for 30 secs, annealing at $51^{\circ} \mathrm{C}$ for 30 secs and extension at $72^{\circ} \mathrm{C}$ for 45 secs. Final polymerization was conducted at $72^{\circ} \mathrm{C}$ for $5 \mathrm{~min}$.

\subsection{Electrophoresis}

The PCR products were analysed in 1\% agarose (Bio world-USA) gel. Electro- 
phoresis was performed at 100 volts for 50 minutes and PCR products along with 100 bp ladder were observed using ultraviolet trans-illuminator.

\subsection{DNA Sequencing}

Sanger sequencing (Chain termination method) approach has been employed for DNA sequencing in this study. Sequencing data was analysed by using Molecular Evolutionary Genetics Analysis (MEGA) software version 7.0 [22].

\section{Results}

Amplicon size of 840 bp of spike glycoprotein (S1) was amplified using the specific primers designed from conserved regions of the spike gene among all the reference strains used in this research. A total of 53 samples were screened for detection of antibodies against IBV by HA and virus neutralization test while 43 were found to be positive. Table 1 shows results of 10 samples identified with HI and VNT.

The assay detected both classic and variant strains by using similar protocol. Sequence analysis data revealed that amplicons of different sizes close to IBV variant were due to deletions at various sites. Molecular evolutionary genomic analysis (MEGA-ABI3730XL) was used to compare the test samples and reference strain.

\subsection{Spike Gene Sequence of IBV (Sindh)}

ACTTCGTGTCTACTACCAAGTGCCTTCAGACCACCTGATGGTTGGCATT TACATGGGGGTGCGTATGCGGTTGTTAATATTTCTAGTGAATCTAATA ATGCAGGCTCTTCATCTGGGTGTACTGTTGGTATTATTCATGGTGGTCG TGTTGTTAATGCTTCTTCTATAGCTATGACGGCACCGTCATCAGGTATG GCTTGGTCTAGCAGTCAGTTTTGTACTGCATACTGTAACTTTTCAGATA CTACAGTGTTTGTTACACATTGTTACAAACATGTTGGGTGTCCTATAAC TGGCATGCTTCAACAGCATTCTATACGTGTTTCTGCTATGAAAAATGGC CAGCTTTTTTATAATTTAACAGTTAGTGTAGCTAAGTACCCTACTTTTA AATCATTTCAGTGTGTTAATAATTTAACATCCGTATATTTAAATGGTGA TCTTGTTTACACCTCTAATGAGACCACAGATGTTACATCTGCAGGTGTT TATTTTAAAGCTGGTGGACCTATAACTTATAAAGTTATGAGAGAAGTT AGAGCCCTGGCTTATTTTGTTAATGGT.

Table 1. Isolates resemblance based on PCR, VNT and nucleotide sequencing in results.

\begin{tabular}{cccc}
\hline Code No & Isolate Designation & $\begin{array}{c}\text { Identification method } \\
\text { HI and VNT }\end{array}$ & $\begin{array}{c}\text { Genotype } \\
\text { Resemblance }\end{array}$ \\
\hline 1 & $($ chicken/Op-KRI/H120/16) & H120 & Classic \\
2 & $($ chicken/Op-KRI/H120/16) & H120 & Classic \\
3 & $($ chicken/Op-KRI/4/91/16) & $4 / 91$ & Vaccinal \\
4 & $($ chicken/Op-KRI/D274/16) & D274 & Vaccinal \\
5 & $($ chicken/Op-KRI/D274/16) & D274 & Vaccinal \\
6 & $($ chicken/Op-LHR/LH120/16) & H120 & Vaccinal \\
7 & $($ chicken/Op-LHR/H120/16) & H120 & Vaccinal \\
8 & $($ chicken/Op-LHR/H120/16) & H120 & Vaccinal \\
9 & $($ chicken/Op-LHR/4/91/16) & $4 / 91$ & Variant \\
10 & $($ chicken/Op-LHR/4/91/16) & $4 / 91$ & Variant
\end{tabular}




\subsection{Spike Gene Sequence of IBV (Punjab)}

TCTTAGTGTACTACTACCAAAGCGCCTTTAGGCCACCTACTGGTTGGC ATTTACATGGAGGTGCTTATGCCGTAGTAAATGTTTCTGAGCAAAATA GTACTGTTACTGGATCAGAATGTACTACGGGTATTATTAGTGGTGGTT ACACTTTTAATGCTTCATCTGTAGCTATGACAGCACCATCTTTAGGTAT GACTTGGTCTAAGATGCAGTTTTGCACGGCTTATTGTAACTTCTCTGAT ATTACAGTGTTTGTTACGCATTGTTATGCAAGCGGGGTTGGTAAATGC CCTTTAACAGGCCTTATTCAACAGAGTCACATTCGCATTTCTGCTATGA GAAATGGTACTTTGTTTTATAATGCTACAGTTAGTACAAATAAGTATCC CAGATTTAAGTCACTTCAATGTGTGGATAATTTCACATCTGTTTATTTA AATGGTGATCTTGTTTTTACTAGTAATCATACTATTATAGTTAAAGAAG CAGGTGTGTACTTTAAAGGGGGT.

Sequence alignment results revealed two distinct sequences due to mutation, deletion and additions of nucleotides at different positions of S1 glycoprotein gene. Samples originated from Sindh province had more number of sequence variations as compared to the samples originated from Punjab province. There was a deletion of " $\mathrm{A}$ " at base position 83 and 94 with reference to sequence reported with Accession No. EU822341. A deletion of six bases from position 358 to 363 was observed in all classic type strains including IBV strain from Sindh, Pakistan. The IBV strain prevalent in Punjab province of Pakistan showed few deletions as compared to reference sequence. Deletions at nucleotide position 177,178 and 179 were found compared to the consensus sequence of IBV variant strains included in the study. In this study two novel mutations has been identified at nucleotide position 177 and 178 in the IBV strains isolated from Punjab province of Pakistan as depicted in Figure 1 and Figure 2.

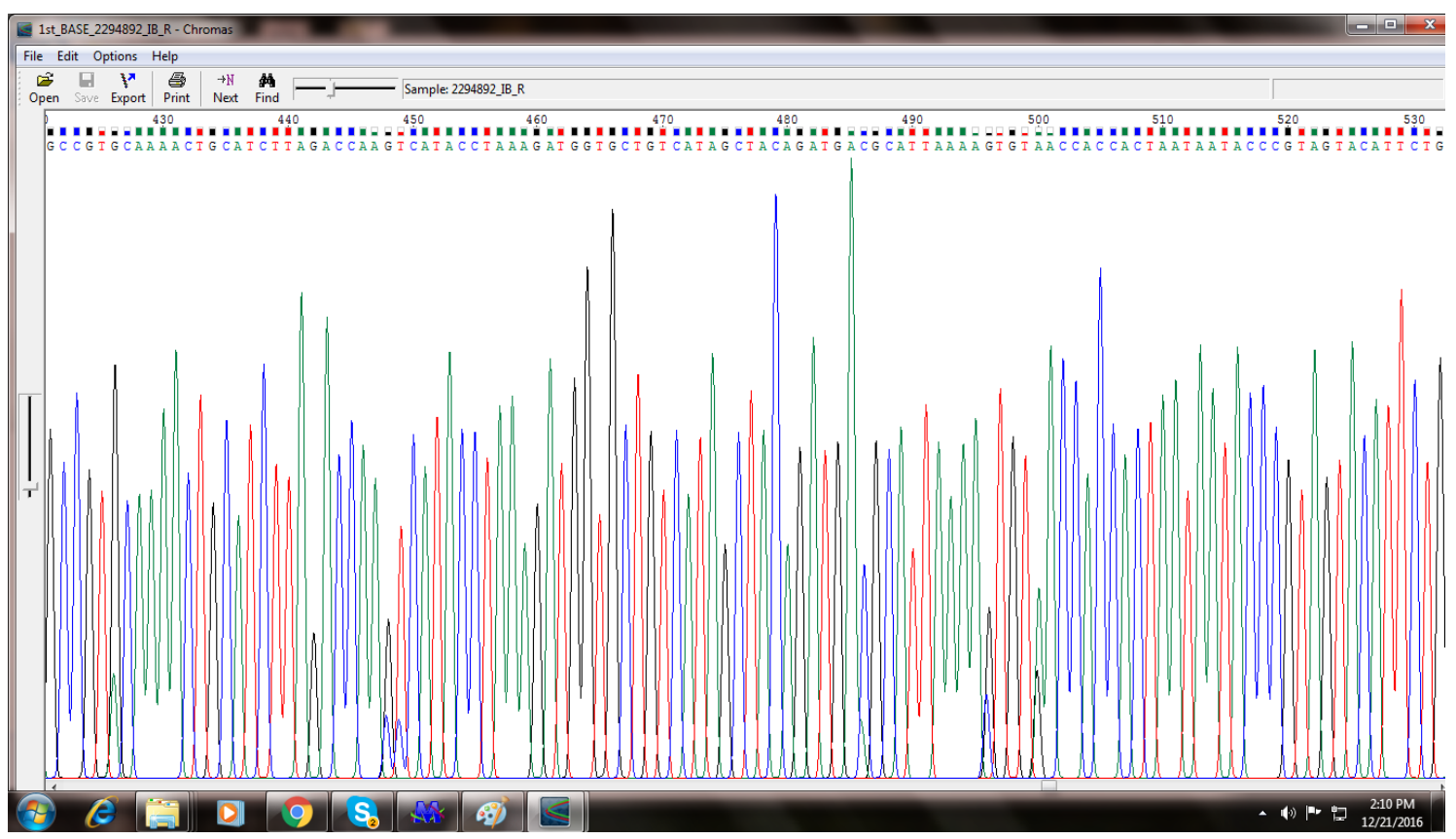

Figure 1. Chromatogram IB nucleotides specificity in sequencing. 
The strains circulating in the Punjab province was associated with QX and $4 / 91$ strains of IBV. The technique was used to construct phylogenetic trees by utilizing a computational tool of Molecular Evolutionary Genetics Analysis (MEGA). The resemblance of strains isolated from Sindh province on the basis of sequences compared to that of reference strains were mostly associated to classic IBV as shown in Figure 3.

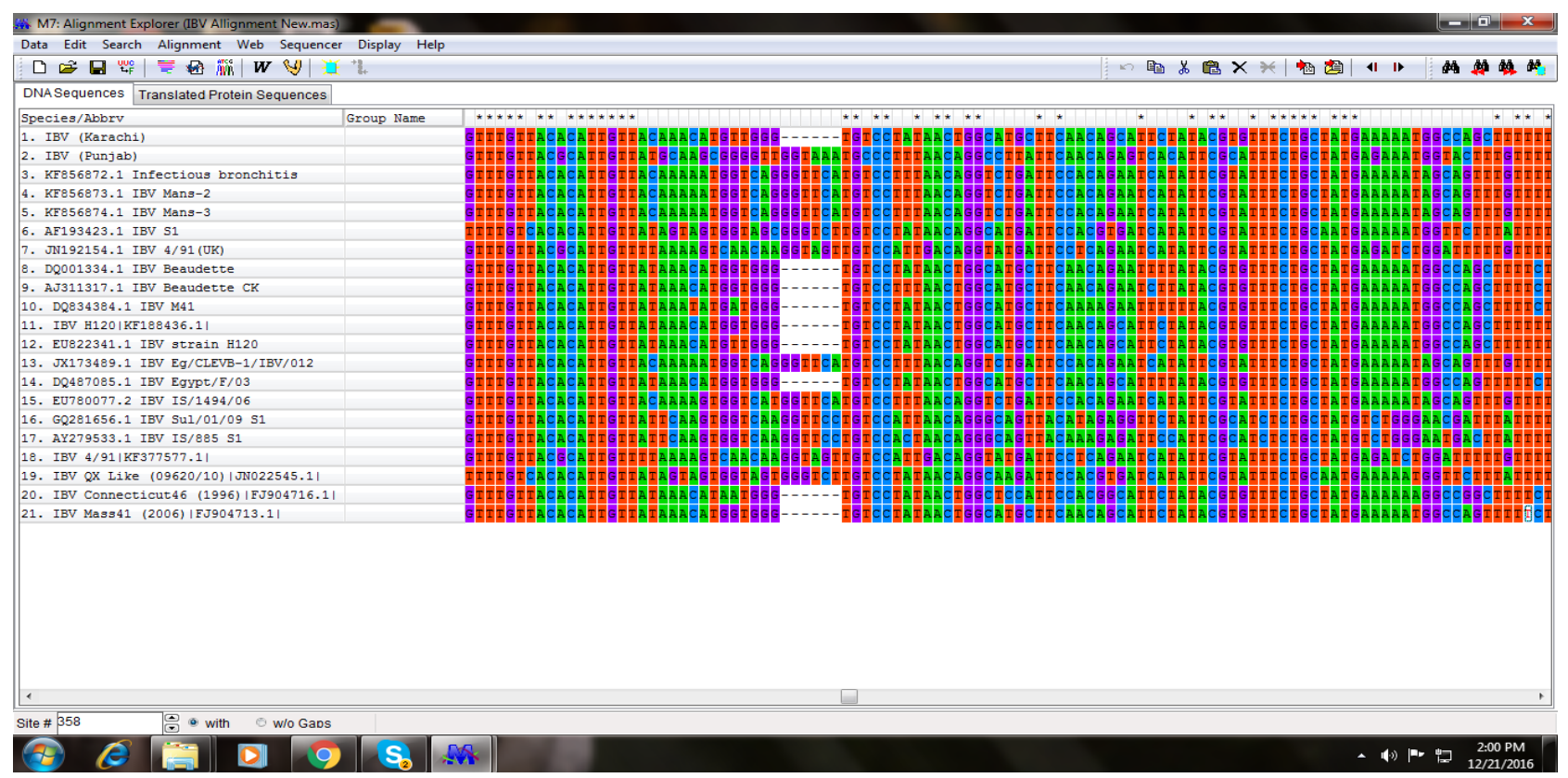

Figure 2. Multiple sequence alignment of S1 glycoprotein genes from different indigenous isolates including classic and variant reference strains.

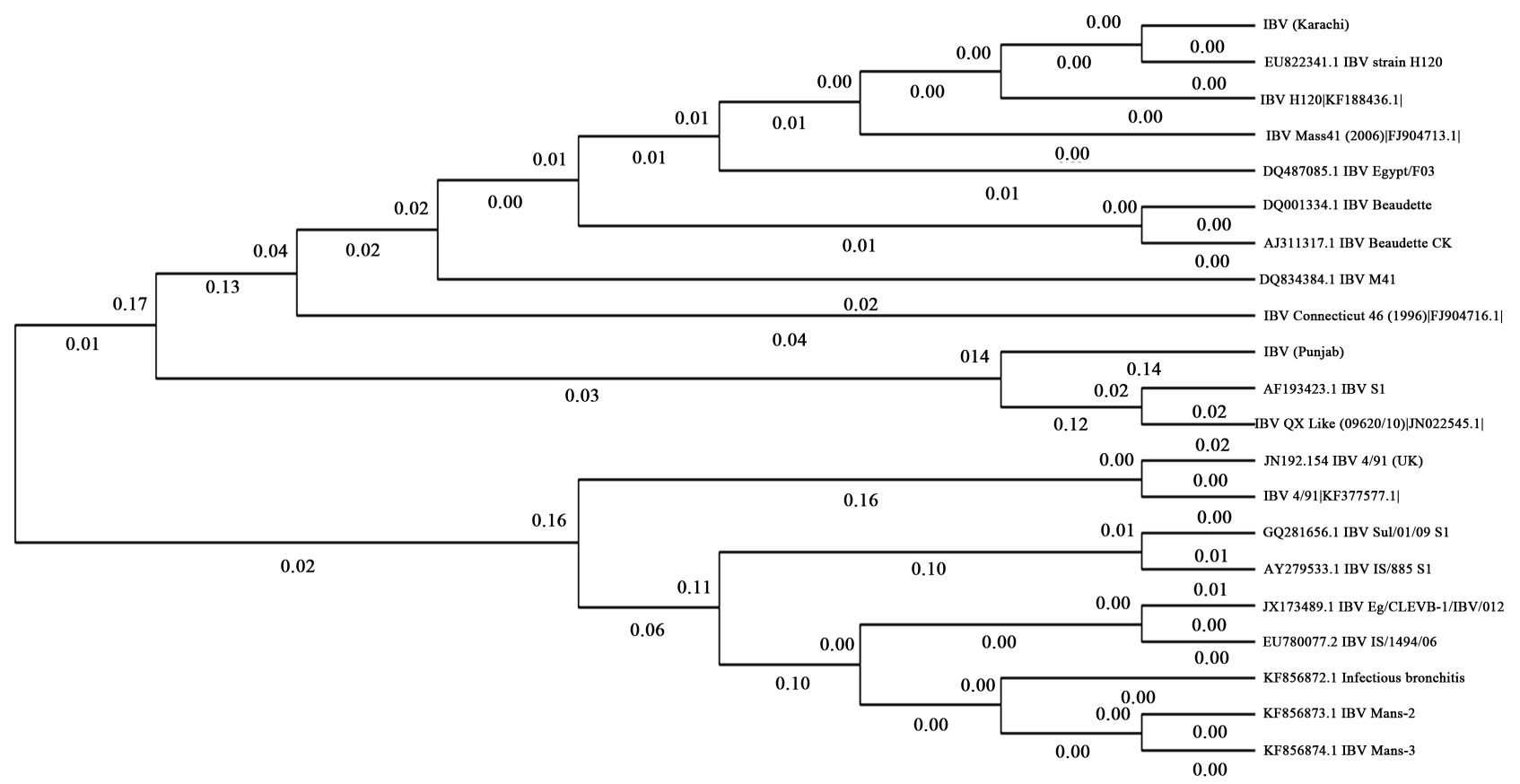

Figure 3. Phylogenetic tree showing various associations \& linkages concerning classics and variant of IBV. 


\section{Discussion}

The present study was conducted to monitor the incidence of infectious bronchitis in commercial chickens in Pakistan. This disease is of significant economic concern for poultry producers in Pakistan [19] and around the globe [8]. The IBV virus also has multiple serotypes. Within IBV more than 20 strains have been identified worldwide [23]. These new strains arise due to rapid recombination, insertions, deletion or point mutation events are predominantly in the $\mathrm{S} 1$ (the spike protein gene) gene resulting in the generation of Massachusetts and Arkansas IBV strains [24].

PCR based diagnosis of the IBV has also been common in diagnostic techniques now a days. The characterization of prevalent field strain in epidemic is necessary to define vaccination strategies in the IBV exposed areas. Many vaccinal strains such as M-41, H120, W93, H52 and 4/91 are extensively used, but they cannot induce effective immune response against IBV [25]. So, the current study was designed with the specific focus to validate the molecular approach to diagnose and further identify the strain of the IBV through sequencing of the partial Spike glycoprotein gene. The field samples were detected positive for IBV producing an amplified fragment of $840 \mathrm{bp}$ and further assigned for the specific strain by sequencing of the gene "Spike gene" responsible for pathogenicity. Molecular characterization of the IBV is recommended by analysis of sequence of the Spike gene. RT-PCR product cycle sequencing is being used to identify field strains of IBV in many countries [26]. For rapid identification of IBV the improvements in RT-PCR had been done [27]. While targeting the partial S1 subunit of Spike protein gene, S1 subunit contains the hyper variable unit which has tendency to rapidly mutate over the short spans of time. The approach to analyse only S1 subunit of Spike protein is quite enough to determine the strain of IBV. However, in present study the region of Spike protein investigated was increased to partial sequence of the S2 subunit as well in order to establish the sequence variations in this region with characterization of IBV.

On the basis of phylogenetic tree and mutation deletion patterns in spike protein gene (S1 Glycoprotein) of IBV strain isolated from Punjab province belonged to the variant type. The neighbouring strains found in phylogenetic tree were Accession No. AF193423.1, JN192154.1, GQ281656.1, AY279533.1, JX173489.1, which all belong to the variant strains of IBV. The result of current study corroborates with the findings of Rafique who revealed that strains of IBV isolated from Pakistan showed maximum nucleotide homology with IBV 4/91 [28]. The IBV strains found in Punjab region of Pakistan exhibited slight variation from the reference sequences (Accession No. JX173489.1 and EU780077.2). The finding of current study is concordant with the already reported sequences (Accession No KF856873.1, GQ281656.1 and AY279533.1). This variation pattern assigns the strain prevalent in this region possess a unique identity which although resides in variant group but with slightly altered sequence pattern.

The strain identified in Sind province of Pakistan belonged to the Classic 
strain cluster of IBV. The neighbouring strains from reference data in the phylogenetic tree were Accession No. EU82234.1, KF188436.1, DQ001334.1, AJ311317.1 and FJ90471641, which all belong to Classic strain of IBV. The results are partially in agreement with the observation of Ahmed who observed that the commercial broiler and layer flock in Pakistan were seropositive with M-41 (88\%) and 4/91 (8\%) strains [29].

Haemagglutination and virus neutralization test have been routinely carried out to diagnose of IBV in different epidemics [29]. However, these techniques cannot diagnose disease accurately due to phenomenon of indirect detection of virus through IgG produced against the virus. Cross reactivity of IgG to be detected is another issue in interpreting the actual results. This study in contrast authenticates the diagnosis of the virus by directly detecting the presence or absence of the genome of virus.

Effective vaccination strategies require accurate and authentic analysis of the prevalent strain of IBV either classic or variant type [30]. The mutation or deletion patterns in spike protein gene confer the identity of the strain either classic or variant. Current results could help the commercial farmers to design vaccinal strategy for effective immunoprophylaxis against IB virus on the basis of confirmation of prevalent strain (variant) in the respective area. Furthermore, this study could also provide the base for further investigation of the disease on molecular patterns which will define the molecular diagnostics and immunoprophylaxis strategies against viral diseases in near future.

\section{Conclusion and Recommendation}

The use of vaccinal strain in different areas of Pakistan for effective immunoprophylaxis shall be homologous to the indigenous wild strain of avian IBV. Phylogenetic analysis of the isolates revealed that molecular sequences of IBV strain which recovered from Sindh and Punjab province of Pakistan showed close resemblance with IBV strain H120 and IBV 4/91 respectively. The use of appropriate homologous strain in vaccines is the pre require of protective immunoprophylaxis in birds against IB virus. Molecular analysis of antibody neutralizing part IB antigen revealed the presence of only two strains across Sindh and Punjab province of Pakistan. Whereas, there are many vaccinal serotypes M-41, H120, W93, H52 and 4/91 are being used for immunoprophylaxis against IBV in the commercial poultry but had not provided protection despite of anti-IBV humoral response. The current study explored the cause of IBV vaccine failure as $\mathrm{S} 1$ glycoprotein in each strain induced specific neutralizing antibody. Therefore, it is recommended that selection of vaccine for effective immunization shall be according to the circulating wild type IBV strain of the respective area.

\section{Acknowledgements}

The authors of the paper are highly grateful to Mr. Usman Farooq Khalid the 
owner of Ottoman Pharma (Immuno Division) for providing financial support, isolate of Infections Bronchitis virus and laboratory facility to execute the research in the best interest of the poultry industry.

\section{Conflicts of Interest}

The authors declare no conflicts of interest regarding the publication of this paper.

\section{References}

[1] Cavanagh, D. (2005) Coronaviruses in Poultry and Other Birds. Avian Pathology, 346, 439-448. https://doi.org/10.1080/03079450500367682

[2] Otsuki, K., Huggins, M.B. and Cook, J.K. (1990) Comparison of the Susceptibility to Avian Infectious Bronchitis Virus Infection of Two Inbred Lines of White Leghorn Chickens. Avian Pathology, 193, 467-475. https://doi.org/10.1080/03079459008418700

[3] Fabricant, J. (1998) The Early History of Infectious Bronchitis. Avian Diseases, 424, 648-650. https://doi.org/10.2307/1592697

[4] Cavanagh, D. and Gelb, J. (2008) Infectious Bronchitis. In: Saif, Y.M., et al. Eds., Iowa State Press, 117-135.

[5] Worthington, K.J., Currie, R.J. and Jones, R.C. (2008) A Reverse Transcriptase Polymerase chain Reaction Survey of Infectious Bronchitis Virus Genotypes in Western Europe. Avian Pathology, 373, 247-257. https://doi.org/10.1080/03079450801986529

[6] Schalk and Hawn (1931) First Report of Infectious Bronchitis in North Dakota. "An Apparently New Respiratory Disease of Chicks". Journal of the American Veterinary Medical Association, 78, 413-422.

[7] Beach, J.R. and Schalm, O.W. (1936) A Filterable Virus, Distinct from That of Laryngorracheitis, the Cause of a Respiratory Disease of Chicks. Poultry Science, 15, 199-206. https://doi.org/10.3382/ps.0150199

[8] De Wit, J.J. (2000) Detection of Infectious Bronchitis Virus. Avian Pathology, 29, 71-93. https://doi.org/10.1080/03079450094108

[9] Endo-Munoz, L.B. and Faragher, J.T. (1989) Avian Infectious Bronchitis: Cross-Protection Studies Using Different Australian Subtypes. Australian Veterinary Journal, 66, 345-348. https://doi.org/10.1111/j.1751-0813.1989.tb09728.x

[10] Lambrechts, C., Pensaert, M. and Ducatelle, R. (1993) Challenge Experiments to Evaluate Cross-Protection Induced at the Trachea and Kidney Level by Vaccine Strains and Belgian Nephropathogenic Isolates of Avian Infectious Bronchitis Virus. Avian Pathology, 22, 577-590. https://doi.org/10.1080/03079459308418945

[11] Muneer, M.A., Newman, J.A., Halvorsan, D.A., Sivanandan, V., Nagaraja, K.V. and Coon, N. (1988) Efficacy of Infectious Bronchitis Virus Vaccines against Heterologous Challenge. Research in Veterinary Science, 45, 22-27. https://doi.org/10.1016/S0034-5288(18)30889-0

[12] Zanaty, A., Arafa, A.S., Hagag, N. and El-Kaddy, M. (2016) Genotyping and Pathotyping of Diversified Strains of Infectious Bronchitis Viruses Circulating in Egypt. World Journal of Virology, 5, 125-134. https://doi.org/10.5501/wjv.v5.i3.125

[13] Lin, S.Y. and Chen, H.W. (2017) Infectious Bronchitis Virus Variants: Molecular Analysis and Pathogenicity Investigation. International Journal of Molecular 
Sciences, 18, Article ID: 2030. https://doi.org/10.3390/ijms18102030

[14] Cavanagh, D., Davis, P.J., Cook, J.K., Li, D., Kant, A. and Koch, G. (1992) Location of the Amino Acid Differences in the S1 Spike Glycoprotein Subunit of Closely Related Serotypes of Infectious Bronchitis Virus. Avian Pathology, 211, 33-43. https://doi.org/10.1080/03079459208418816

[15] Koch, G., Hartog, L., Kant, A. and van Roozelaar, D.J. (1990) Antigenic Domains on the Peplomer Protein of Avian Infectious Bronchitis Virus: Correlation with Biological Functions. Journal of General Virology, 70, 1929-1935. https://doi.org/10.1099/0022-1317-71-9-1929

[16] Schultze, B., Cavanagh, D. and Herrler, G. (1992) Neuraminidase Treatment of Avian Infectious Bronchitis Coronavirus Reveals a Hemagglutinating Activity That Is Dependent on Sialic Acid-Containing Receptors on Erythrocytes. Virology, 1892, 792-794. https://doi.org/10.1016/0042-6822(92)90608-R

[17] Ignjatovic, J. and Galli, L. (1994) The S1 Glycoprotein But Not the N or M Proteins of Avian Infectious Bronchitis Virus Induces Protection in Vaccinated Chickens. Arch Virology, 1381, 117-134. https://doi.org/10.1007/BF01310043

[18] Johnson, M.A., Pooley, C., Ignjatovic, J. and Tyack, S.G. (2003) A Recombinant Fowl Adenovirus Expressing the S1 Gene of Infectious Bronchitis Virus Protects against Challenge with Infectious Bronchitis Virus. Vaccine, 22, 2730-2736. https://doi.org/10.1016/S0264-410X(03)00227-5

[19] Muneer, M.A., Newman, J.A., Goyal, S.M. and Ajmal, M. (1987) Antibodies to Avian Infectious Bronchitis Virus in Pakistani Chickens. Poultry Science, 66, 765-767. https://doi.org/10.3382/ps.0660765

[20] Hofsad, M.S. (1958) Antigenic Difference among Isolates of Avian Infectious Bronchitis Virus. American Journal Veterinary Research, 19, 740-743.

[21] Karaca, K. and Naqi, S. (1993) A Monoclonal Antibody Blocking ELISA to Detect Serotype-Specific Infectious Bronchitis Virus Antibodies. Veterinary Microbiology, 34, 249-257. https://doi.org/10.1016/0378-1135(93)90015-Y

[22] Kumar, S., Stecher, G. and Tamura, K. (2016) MEGA7: Molecular Evolutionary Genetics Analysis Version 7.0 for Bigger Datasets. Molecular Biology and Evolution, 33, 1870-1874. https://doi.org/10.1093/molbev/msw054

[23] Lee, C.W. and Jackwood, M.V. (2000) Evidence of Genetic Diversity Generated by Recombination among Avian Coronavirus IBV. Archives of Virology, 145, 2135-2148. https://doi.org/10.1007/s007050070044

[24] Wang, L., Junker, D. and Collisson, E.W. (1993) Evidence of Natural Recombination within the S1 Gene of Infectious Bronchitis Virus. Virology, 192, 710-716. https://doi.org/10.1006/viro.1993.1093

[25] Liu, S. and Kong, X. (2004) A New Genotype of Nephropathogenic Infectious Bronchitis Virus Circulating in Vaccinated and Non-Vaccinated Flocks in China. Avian Pathology, 33, 321-327. https://doi.org/10.1080/0307945042000220697

[26] Zwaagstra, K.A., Van der Zeijst, B.A.M. and Kusters, J.G. (1992) Rapid Detection and Identification of Avian Infectious Bronchitis Virus. Journal of Clinical Microbiology, 30, 79-84.

[27] Lee, C.W., Hilt, D.A. and Jackwood, M.W. (2003) Typing of Field Isolates of Infectious Bronchitis Virus Based on the Sequence of the Hypervariable Region in S1 Gene. Journal of Veterinary Diagnostic Investigation, 15, 344-348. https://doi.org/10.1177/104063870301500407

[28] Rafique, S., Naeem, K., Sadique, N., Abbas, M., Shah, A.A., Ali, A., Rahim, A. and 
Rashid, F. (2018) Determination of Genetic Variability in Avian Infectious Bronchitis Virus (AIBV) Isolated from Pakistan. Pakistan Journal of Zoology, 50, 695-701. https://doi.org/10.17582/journal.pjz/2018.50.2.695.701

[29] Ahmed, Z., Naeem, K. and Hameed, A. (2007) Detection and Seroprevalence of Infectious Bronchitis Virus Strains in Commercial Poultry in Pakistan. Poultry Science, 86, 1329-1335. https://doi.org/10.1093/ps/86.7.1329

[30] Boursnell, M.E.G. (1987) Completion of the Sequence of the Genome of the Coronavirus Avian Infections Bronchitis Virus. Journal of General Virology, 68, 57-77. https://doi.org/10.1099/0022-1317-68-1-57 